\title{
Molecular characterization of Cryptosporidium spp. and Giardia duodenalis from yaks in the central western region of China
}

\author{
Meng $\mathrm{Qi}^{1,2}$, Jinzhong Cai ${ }^{3}$, Rongjun Wang ${ }^{1,2}$, Junqiang $\mathrm{Li}^{1,2}$, Fuchun Jian ${ }^{1,2^{*}}$, Jianying Huang ${ }^{1,2}$, Huan Zhou ${ }^{1,2}$
} and Longxian Zhang ${ }^{1,2^{*}}$

\begin{abstract}
Background: Cryptosporidium spp. and Giardia duodenalis are important causes of diarrheal diseases in humans and animals worldwide, and there is an increased interest in the role of animals in the mechanical transmission of these protozoa. To examine the role of yaks in this process, we examined the occurrence and genotypes of Cryptosporidium and $G$. duodenalis in yaks in western China.

Results: A total of 545 fecal specimens were collected from yaks from nine different counties in the central western region of China. The prevalence for Cryptosporidium spp. and G. duodenalis were $4.0 \%$ (22/545) and $6.0 \%$ (16/545), respectively. Mixed infections of Cryptosporidium and G. duodenalis were also detected in four specimens. The prevalence of both protozoa differed significantly between some age groups, with higher rates of infection in animals $<1$ year old. Sequence analysis of the small subunit rRNA (SSU rRNA) gene of the Cryptosporidium isolates identified the species as C. parvum $(n=12)$, C. bovis $(n=6)$, C. ryanae $(n=3)$, and C. ubiquitum $(n=1)$. Genotyping based on 60-kDa glycoprotein (gp60) gene from five C. parvum isolates identified all as Ild with three isolates identified as IIdA15G1, one as IIdA18G1, and one as IIAA19G1. One C. ubiquitum isolate was identified as subtype Vlla. Amongst the G. duodenalis isolates, 16 were identified as assemblage E at the SSU rRNA gene. Four novel glutamate dehydrogenase (gdh) subtypes and two triosephosphate isomerase (tpi) subtypes were found amongst the G. duodenalis assemblage $\mathrm{E}$ isolates.

Conclusions: The presence of C. parvum subtype IIdA15G1, IIdA18G1, and IIdA19G1 isolates further confirms the dominance of the C. parvum Ild subtypes in China. These findings also indicate that yaks may be a source of zoonotic Cryptosporidium infection, and this is the first report of G. duodenalis in yaks. The data presented here provides the basis for further genotyping or subtyping studies of $G$. duodenalis in yaks.
\end{abstract}

Keywords: Cryptosporidium, Giardia duodenalis, Yaks, Genotyping, Subtyping

\section{Background}

Cryptosporidium and Giardia are common parasitic protists that mainly cause enteric disease in humans and animals, including livestock, companion animals, and wildlife $[1,2]$. Cryptosporidiosis and giardiasis result from fecal-oral transmission of oocysts or cysts, usually via water, food, or direct contact [3-5]. Livestock are often implicated in the disease cycle, and have been identified as

\footnotetext{
*Correspondence: jfchun2008@163.com; zhangl×8999@gmail.com

${ }^{1}$ College of Animal Science and Veterinary Medicine, Henan Agricultural University, Zhengzhou 450002, P. R. China

${ }^{2}$ International Joint Research Laboratory for Zoonotic Diseases of Henan,

Zhengzhou 450002, P. R. China

Full list of author information is available at the end of the article
}

the sources of several foodborne and waterborne outbreaks of human cryptosporidiosis and giardiasis [4-6].

To date, 26 Cryptosporidium species and more than 70 genotypes have been recognized [7, 8]. Giardia duodenalis (syn. G. lamblia, G. intestinalis) is considered a multispecies complex, with at least eight distinct genetic groups or assemblages $(\mathrm{A}-\mathrm{H})$ based on protein or DNA polymorphisms [1]. C. hominis, C. parvum, and G. duodenalis assemblages $\mathrm{A}$ and $\mathrm{B}$ are responsible for the majority of known human disease cases [4]. Molecular epidemiological studies conducted in various countries suggest that cattle may be a significant reservoir of Cryptosporidium and G. duodenalis, with potential for 
zoonotic transfer to humans [3, 4]. Cattle have been identified as the primary host for five Cryptosporidium species (C. andersoni, C. bovis, C. parvum, C. ryanae, and $C$. ubiquitum), and with the exception of $C$. ryanae, all of these species can also cause infection in humans [2, 9-12]. For G. duodenalis, assemblage $\mathrm{E}$ is the most commonly reported genotype in cattle, followed by assemblages $A$ and $B[13,14]$.

All known species and genotypes of both Cryptosporidium and G. duodenalis have been reported worldwide in dairy and beef cattle. In contrast, very little is known about the prevalence and molecular characteristics of these pathogens in other members of the family Bovidae, including yaks (Bos grunniens). There has been wide variation in the reported prevalence of Cryptosporidium in fecal specimens from yaks in China using microscopy, enzyme immunoassays, and molecular tools for identification (5.26-39.7 \%) [8, 15-24]. To date, six Cryptosporidium species (C. andersoni, C. bovis, C. parvum, $C$. ryanae, $C$. ubiquitum, and $C$. xiaoi) and three genotypes, which have been identified in yaks $[8,17,18,20,24]$. However, G. duodenalis has not been reported in yaks. The objectives of the present study were to identify the species and/or genotypes of Cryptosporidium and G. duodenalis infecting yaks in western China, and to clarify their public health significance.

\section{Results}

The prevalence of Cryptosporidium spp.

We have collected a total number of 545 fresh yak fecal samples from 9 locations in the central western region of China between 2009-2012 to study the prevalence of Cryptosporidium spp. and G. duodenalis by PCR and sequence analysis (Fig. 1). Among them, 22 specimens were Cryptosporidium-positive by PCR amplification of the SSU rRNA gene, with an overall prevalence of $4.0 \%(22 / 545)$. The prevalence of Cryptosporidium from animals at the different collection sites ranged from 0-11.8\%, with the highest prevalence in Henan County (Table 1). The most common species was $C$. parvum (12 specimens), followed by $C$. bovis ( 6 specimens) (Table 1 ). Results of the $\chi^{2}$ test showed that the differences in Cryptosporidium prevalence was not statistically significant between sampling sites $\left(p>0.05, \chi^{2}=14.17\right)$. However, the prevalence were significantly different between different age groups $(p<0.01$, $\left.\chi^{2}=8.42\right)$, with the higher prevalence $(6.6 \%)$ observed in animals $<1$ year old than animals $>1$ year old $(1.5 \%)$.

Subtyping analysis at the gp 60 gene was successful for five of the 12 C. parvum isolates, and all were identified as belonging to family IId: three were IIdA15G1, one was IIdA18G1, and one was IIdA19G1 (Table 1). One $C$. ubiquitum isolate was subtyped as family XIIa [GenBank: KP334140].

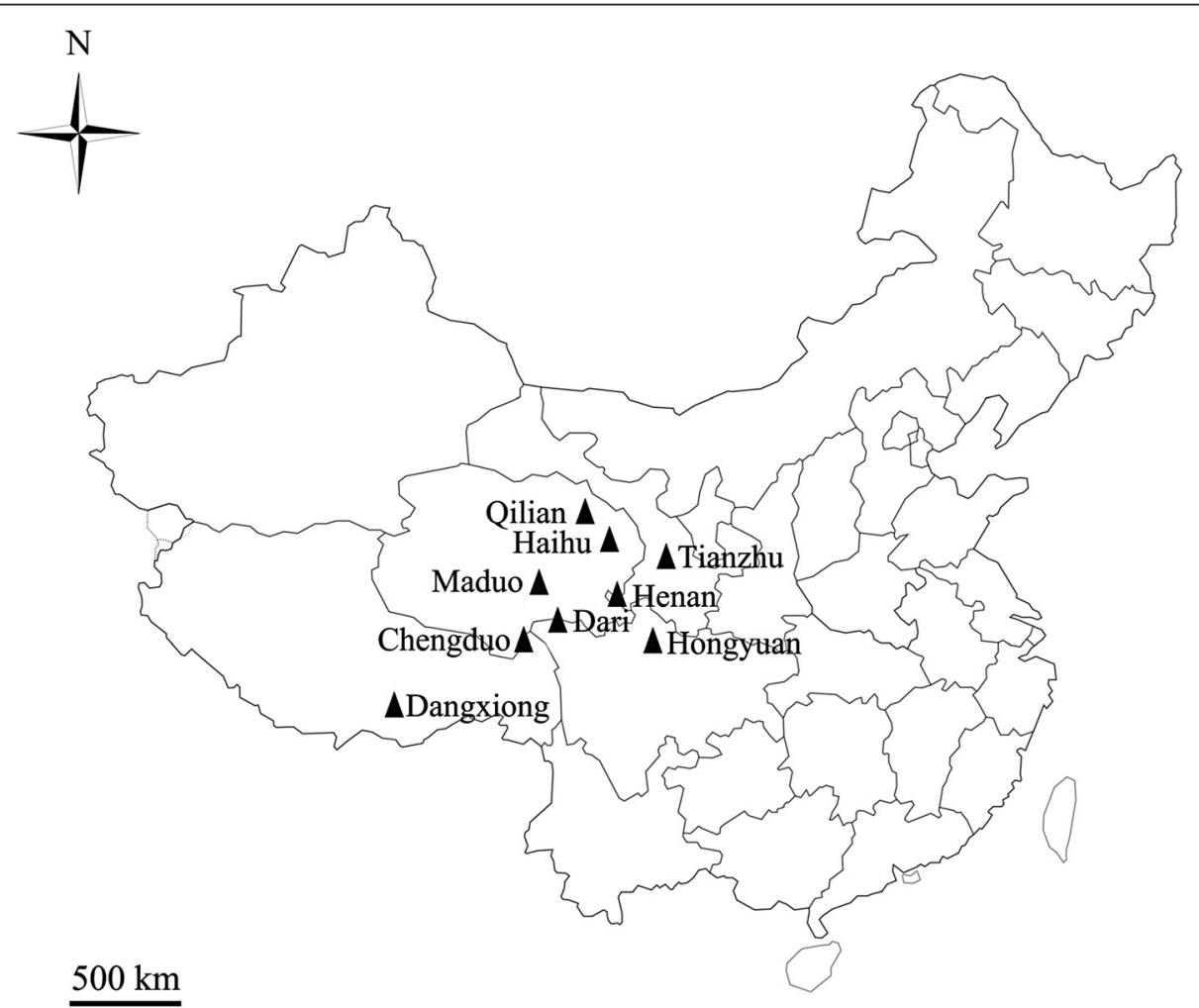

Fig. 1 Specific locations at which specimens were collected in this study. $\mathbf{\Delta}$ study locations 
Table 1 Prevalence and species/subtype distributions of Cryptosporidium spp. in yaks

\begin{tabular}{|c|c|c|c|c|c|c|}
\hline \multirow[t]{3}{*}{ Location } & \multirow{3}{*}{$\begin{array}{l}\text { No. of } \\
\text { yaks }\end{array}$} & \multirow[t]{3}{*}{ No. positive (\%) } & \multicolumn{4}{|l|}{ Age } \\
\hline & & & \multicolumn{2}{|l|}{$<1$ year } & \multicolumn{2}{|l|}{$>1$ year } \\
\hline & & & No. positive/No. of yaks & Species (n)/subtype (n) & No. positive/No. of yaks & Species (n)/subtype (n) \\
\hline Tianzhu & 117 & $7\left(6.0,4.1-\left.7.9 C\right|^{a}\right)$ & $5 / 40$ & $\begin{array}{l}\text { C. bovis (1), C. ryanae (2), } \\
\text { C. parvum (2)/IIA15G1 (2) }\end{array}$ & $2 / 77$ & $\begin{array}{l}\text { C. bovis (1), } \\
\text { C. ubiquitum (1)/XIla (1) }\end{array}$ \\
\hline Dangxiong & 44 & $4(9.1,4.7-13.8 \mathrm{Cl})$ & $4 / 44$ & C. parvum (4)/IdA19G1 (1) & & \\
\hline Hongyuan & 84 & $1(1.2,0-2.9 \mathrm{Cl})$ & $1 / 36$ & C. parvum (1) & $0 / 48$ & \\
\hline \multirow[t]{2}{*}{ Henan } & 34 & $4(11.8,6.2-17.4 \mathrm{Cl})$ & $3 / 21$ & C. bovis (1), & $1 / 13$ & C. bovis (1) \\
\hline & & & & C. parvum (2)/IdA15G1 (1) & & \\
\hline \multirow[t]{2}{*}{ Dari } & 62 & $2(3.2,0.5-5.9 \mathrm{Cl})$ & $2 / 30$ & C. bovis (1), & $0 / 32$ & \\
\hline & & & & C. parvum (2)/IdA18G1 (1) & & \\
\hline Haihu & 66 & $2(3.0,0.5-5.5 \mathrm{Cl})$ & $1 / 34$ & C. parvum (1) & $1 / 32$ & C. parvum (1) \\
\hline Maduo & 39 & $1(2.6,0-6.2 \mathrm{Cl})$ & $1 / 20$ & C. ryanae (1) & 0/19 & \\
\hline Qilian & 47 & $1(2.1,0-5.1 \mathrm{Cl})$ & $1 / 25$ & C. bovis (1) & $0 / 22$ & \\
\hline Chengduo & 52 & 0 & $0 / 24$ & & $0 / 28$ & \\
\hline Total & 545 & $22(4.0,3.5-4.5 \mathrm{Cl})$ & $18 / 274(6.6)^{b}$ & $\begin{array}{l}\text { C. bovis (4), C. ryanae (3), } \\
\text { C. parvum (11)/IIdA15G1 (3), } \\
\text { IdA18G1 (1). IdA19G1 (1) }\end{array}$ & $4 / 271(1.5)^{c}$ & $\begin{array}{l}\text { C. bovis (2), C. parvum (1), } \\
\text { C. ubiquitum (1)/XIla (1) }\end{array}$ \\
\hline
\end{tabular}

${ }^{a} \mathrm{Cl}: 95 \%$ confidence intervals

${ }^{b}$ and ${ }^{c}$ have significant difference

Mixed infections of both Cryptosporidium and G. duodenalis were also detected in four specimens: two from Tianzhu County, one from Henan County, and one from Dari County.

The prevalence of $G$. duodenalis

A total of 16 specimens showed positive amplification of the SSU rRNA gene, all belonging to the assemblage E. The overall prevalence for $G$. duodenalis carriage was $2.9 \%(16 / 545)$. The nucleotide sequences were identical to a reference sequence from a dairy cattle isolate in China [GenBank: KF843921]. The prevalence of G. duodenalis at the different collected sites ranged from 0 $5.9 \%$, with the highest prevalence in Henan County (Table 2). The prevalence was not statistically significant at different sampling sites $\left(p>0.05, \chi^{2}=5.06\right)$; however, significant difference was observed between the prevalence in different age groups $\left(p<0.01, \chi^{2}=8.62\right)$, with the higher prevalence $(5.1 \%)$ observed in animals $<1$ year old than animals $>1$ year old $(0.7 \%)$.

Table 2 Prevalence and assemblages of Giardia duodenalis in yaks

\begin{tabular}{|c|c|c|c|c|c|c|}
\hline \multirow[t]{3}{*}{ Location } & \multirow{3}{*}{$\begin{array}{l}\text { No. of } \\
\text { yaks }\end{array}$} & \multirow[t]{3}{*}{ No. positive (\%) } & \multicolumn{4}{|l|}{ Age } \\
\hline & & & \multicolumn{2}{|l|}{$<1$ year } & \multicolumn{2}{|l|}{$>1$ year } \\
\hline & & & No. positive/No. of yaks & Assemblage $(n)$ & No. positive/No. of yaks & Assemblage (n) \\
\hline Tianzhu & 117 & $4\left(3.4,1.7-5.1 \mathrm{Cl}^{\mathrm{a}}\right)$ & $3 / 40$ & E (3) & $1 / 77$ & $E(1)$ \\
\hline Dangxiong & 44 & 0 & $0 / 44$ & & & \\
\hline Hongyuan & 84 & $1(1.2,0-2.9 \mathrm{Cl})$ & $1 / 36$ & $E(1)$ & $0 / 48$ & \\
\hline Henan & 34 & $2(5.9,1.1-10.7 \mathrm{Cl})$ & $2 / 21$ & $E(2)$ & $0 / 13$ & \\
\hline Dari & 62 & $3(4.8,1.7-7.7 \mathrm{Cl})$ & $3 / 30$ & $E(3)$ & $0 / 32$ & \\
\hline Haihu & 66 & $3(4.5,1.7-7.3 \mathrm{Cl})$ & $3 / 34$ & $E(3)$ & $0 / 32$ & \\
\hline Maduo & 39 & $1(2.6,0-6.2 \mathrm{Cl})$ & $0 / 20$ & & $1 / 19$ & $E(1)$ \\
\hline Qilian & 47 & $1(2.1,0-5.1 \mathrm{Cl})$ & $1 / 25$ & $E(1)$ & $0 / 22$ & \\
\hline Chengduo & 52 & $1(1.9,0-4.6 \mathrm{Cl})$ & $1 / 24$ & $E(1)$ & $0 / 28$ & \\
\hline Total & 545 & $16(2.9,2.4-3.4 \mathrm{Cl})$ & $14 / 274(5.1)^{b}$ & $E(14)$ & $2 / 271(0.7)^{c}$ & $E(2)$ \\
\hline
\end{tabular}

${ }^{\mathrm{a}} \mathrm{Cl}: 95 \%$ confidence intervals

${ }^{b}$ and ${ }^{c}$ have significant difference 
The genetic diversity of the G. duodenalis assemblage $E$ isolates was determined by amplification and sequencing of the tpi, gdh, and $\beta$-giardin $(b g)$ genes, with 11 $t p i$, six $g d h$, and three $b g$ gene sequences obtained (Table 3$)$. Subtype E1 $(n=7)$ was the most common subtype at the tpi gene. At the gdh gene, four subtypes of assemblage E sequences have not been reported previously.

To clarify the genetic relationships between the different subtypes, alignment and phylogenetic analysis of the obtained tpi and $g d h$ sequences with reference sequences were performed. The phylogenetic analysis of tpi sequences in this study with the reference subtypes AI, AII, subtypes E from cattle, goat and sheep demonstrated that subtypes E1 [GenBank: KP334141] and E4 [GenBank: KP334144] clustered with reference subtypes E, whereas subtypes E2 [GenBank: KP334142] and E3 [GenBank: KP334143] formed one separate cluster in assemblage E (Fig. 2a). Alignment and phylogenetic analysis of the obtained $g d h$ sequences with reference sequences indicated the presence of only G. duodenalis subtype $E$ from cattle and sheep, although the genetic variation was noticed within this subtype (Fig. 2b).

\section{Discussion}

In the present study, the prevalence of Cryptosporidium and G. duodenalis in yaks in western China was $4.0 \%$ and $2.9 \%$, respectively. To the best of our knowledge, this is the first report of G. duodenalis in yaks. The prevalence of Cryptosporidium species appears to vary widely depending on the geographic area in China. The

Table 3 Assemblages of Giardia duodenalis determined by sequence analysis of the SSU rRNA, gdh, tpi, and bg genes of each positive specimen

\begin{tabular}{lllllll}
\hline Yaks ID & Location & Age & SSU rRNA & tpi & gdh & bg \\
\hline M2 & Tianzhu & 3 months & E & E1 & & \\
M22 & Tianzhu & 3 months & E & E2 & & \\
M30 & Tianzhu & 4 months & E & & & \\
M69 & Tianzhu & 3 years & E & & & \\
607 & Henan & 6 months & E & E3 & E1 & E1 \\
615 & Henan & 6 months & E & E3 & & E1 \\
702 & Dari & 7 months & E & E3 & E2 & \\
708 & Dari & 8 months & E & & E2 & \\
711 & Dari & 8 months & E & E3 & E3 & E1 \\
768 & Haihu & 6 months & E & & & \\
772 & Haihu & 6 months & E & E4 & E4 & \\
777 & Haihu & 6 months & E & E4 & E5 & \\
947 & Maduo & 2 years & E & E3 & & \\
978 & Qilian & 8 months & E & E3 & & \\
1045 & Chengduo & 6 months & E & E3 & & \\
1148 & Hongyuan & 3 months & E & & & \\
\hline
\end{tabular}

overall Cryptosporidium prevalence in this study was similar to that reported by Qin et al. (5.26 \%) [24], but was lower than the majority of reported rates (10.4$39.7 \%$ ) [8, 15-23]. Infection rates are affected by many factors, including animal age, specimen size, diagnostic tests, management systems, seasons, and geographic area. Therefore, it is difficult to compare prevalence data between studies. However, similar to our results, previous studies have shown that weaned calves and yearlings are more frequently infected with Cryptosporidium than older yaks $[8,20]$. The overall $G$. duodenalis infection rate in this study is lower than rates recently reported in diary cattle in Heilongjiang Province $(5.2 \%, 41 / 814)$ and Henan Province $(7.2 \%, 128 / 1777)$, China $[25,26]$. We also determined that there was a statistically significant difference in G. duodenalis infection rates between the different age groups. This finding was similar to previous reports regarding giardiasis as a common infection in immature animals [25-27].

To date, in addition to the four most common Cryptosporidium species (C. parvum, C. andersoni, C. bovis, and $C$. ryanae), $C$. ubiquitum and $C$. xiaoi have also been identified in a small number of yaks [8, 20, 24]. A previous study of Cryptosporidium in yaks in Qinghai Province reported that $C$. bovis was the most common species $(31 / 55,56.4 \%)$, followed by C. parvum (16/55, $29.1 \%)$, and C. ryanae (5/55, $9.0 \%$ ) [20]. However, another study of Cryptosporidium in yaks in the same area reported that C. bovis $(56 / 98,57.1 \%)$ and C. ryanae (33/ $98,33.7 \%$ ) were the most common species [8], followed by $C$. andersoni (2/98, $2.0 \%)$, C. ubiquitum (1/98, $1.0 \%)$, and C. xiaoi (1/98, $1.0 \%)$, and that C. parvum was not detected. The results of these previous studies suggest that there is some variation in the dominant species causing cryptosporidiosis in yaks in Qinghai Province. Of the four Cryptosporidium-positive specimens in Tianzhu County, three were identified as C. bovis and one was identified as $C$. andersoni, which is similar to a previous study showing that $C$. bovis is most prevalent in yaks [24]. In the present study, four Cryptosporidium species were identified in yaks, with the most abundant species being C. parvum (12/22, $54.5 \%)$. This result differs from previous reported in yaks, whereas agrees with most previous reports in dairy calves found that C. parvum was the most common species, especially in preweaned dairy calves in the Ningxia Hui Autonomous Region, northwestern China [28-31].

Of the four species identified, $C$. parvum is a major pathogen in humans, while C. ubiquitum has been identified in many human cases of cryptosporidiosis in the United Kingdom, Slovenia, the United States, Canada, Spain, and New Zealand [3, 32]. Of the 22 Cryptosporidium-positive isolates typed at the SSU rRNA gene, 12 were $C$. parvum and one was $C$. ubiquitum. The $C$. 

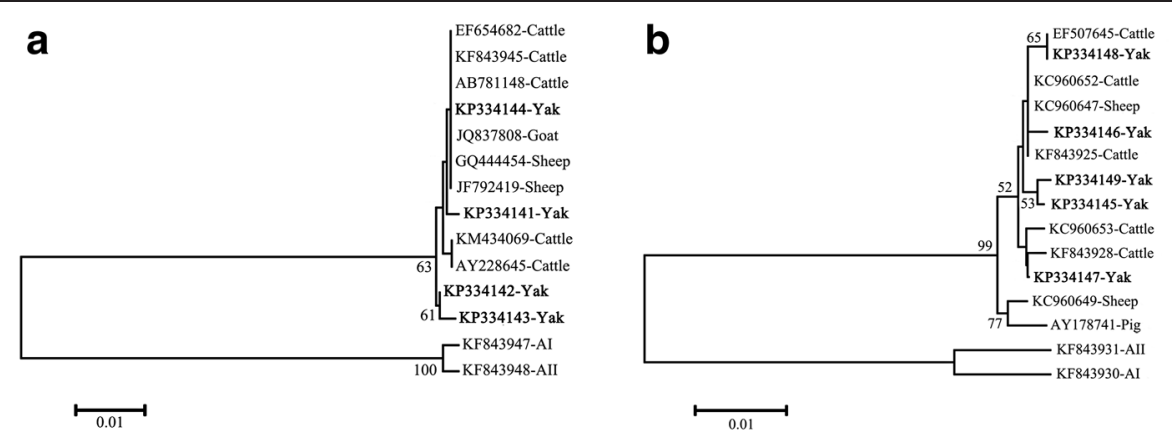

Fig. 2 Dendrograms of Giardia duodenalis based on nucleotide sequences of the triosephosphate isomerase (tpi) (a) and glutamate dehydrogenase ( $g d h)(\mathbf{b})$ gene. Trees were constructed using the neighbor-joining method based on genetic distance calculated by the Kimura 2-parameter model, implemented in MEGA version 5.2. Bootstrap values > 50 \% from 1,000 replicates are shown on nodes. Sequences from this study are marked by filled triangles

ubiquitum isolate belonged to the family XIIa subtype of gp60, which has been detected in goats in China, as well as in humans and other animals in multiple countries [32-34]. Five of the C. parvum isolates were identified as belonging to the IId subtype, and differ from the IIa subtype isolates found in yaks in Qinghai Province [8]. Generally, of the $14 \mathrm{C}$. parvum subtypes (IIa-IIi, and IIk-IIo), IIa and IId are most commonly associated with zoonosis, while subtypes IIc and IIe are anthroponotic subtype families [35]. In general, the C. parvum subtypes found in China appear to be unique. While Mi et al. [8, 34] reported C. parvum subtype IIa isolates in yaks and goats, Ye et al. [36] reported subtype IIc isolate in monkeys, all other C. parvum isolates from China have belonged to IId subtypes, including IIdA15G1 in rodents and cattle [28, 29], and IIdA19G1 in cattle, humans, goats, and urban wastewater [30, 31, 34, 37, 38]. Subtype IIdA18G1 has previously been reported in calves in Serbia and Montenegro [39], in lambs in Spain [40], and in humans in Kuwait and the United Kingdom [41, 42]. In the present study, C. parvum subtype IIdA15G1 was the predominant subtype in yaks in western China, which further confirms the dominance of the C. parvum IIdA15G1 subtype in western China.

Numerous molecular epidemiological data have shown that most cattle, sheep, and pigs are infected with the host-specific G. duodenalis assemblage E (livestock genotype) [1]. Although G. duodenalis assemblage A and $\mathrm{B}$ isolates have been detected in cattle in China, most test-positive specimens have been confirmed as assemblage E $[25,26,29]$. A recent study reported that G. duodenalis assemblage $\mathrm{E}$ may cause intestinal lesions, leading to calf scours [43]. In the present study, sequence analyses indicated that the yaks were also infected with livestock-specific G. duodenalis assemblage E. The previous study in Heilongjiang and Henan Provinces, China, found that the G. duodenalis assemblage $\mathrm{E}$ subtypes in cattle may represent the endemic genetic characteristics $[25,26,44]$. Similar to previous reports, the current study also identified a high level of genetic polymorphism within assemblage $\mathrm{E}$ isolates in yaks by subtyping tpi and $g d h$ sequences. More data from largescale molecular epidemiological investigations focusing in assemblage E strains will clarify the geographical distribution of this pathogen.

\section{Conclusion}

Cryptosporidium parvum is the predominant species in yaks in the study area, which differs from previous reports in Qinghai Provinces that identified C. bovis as the most common species. The presence of $C$. parvum subtype IIdA15G1, IIdA18G1, and IIdA19G1 isolates further confirms the dominance of the C. parvum IId subtypes in China. These findings indicate that yaks may be a source of zoonotic Cryptosporidium. This is the first report of G. duodenalis in yaks, and the obtained data provide useful information for further genotyping or subtyping studies of $G$. duodenalis. More studies are required to determine the dramatic geographic differences in the prevalence of zoonotic Cryptosporidium and $G$. duodenalis in bovine animals in China.

\section{Methods}

\section{Ethics statement}

This study was performed according to the recommendations of the Guide for the Care and Use of Laboratory Animals of the Ministry of Health, China. The research protocol was reviewed and approved by the Research Ethics Committee of Henan Agricultural University. Permission was obtained from the animals' owners prior to the collection of fecal specimens.

\section{Study area and specimen collection}

From August 2009 to September 2012, fresh fecal specimens were collected from yaks from 9 locations in the central western region of China (Fig. 1). Collection sites 
included: Henan, Dari, Haihu, Maduo, Qilian, and Chengduo counties in Qinghai Province $\left(89^{\circ} 35^{\prime} \mathrm{E}-103^{\circ} 04^{\prime} \mathrm{E}, 31^{\circ}\right.$ $\left.90^{\prime} \mathrm{N}-39^{\circ} 19^{\prime} \mathrm{N}\right)$; Tianzhu county in Gansu Province (102 $\left.07^{\prime} \mathrm{E}-103^{\circ} 46^{\prime} \mathrm{E}, 36^{\circ} 31^{\prime} \mathrm{N}-37^{\circ} 55^{\prime} \mathrm{N}\right)$; Dangxiong county in the Xizang Tibetan Autonomous Region $\left(90^{\circ} 45^{\prime} \mathrm{E}-91^{\circ} 31^{\prime} \mathrm{E}\right.$, $\left.29^{\circ} 31^{\prime} \mathrm{N}-31^{\circ} 04^{\prime} \mathrm{N}\right)$; Hongyuan county in Sichuan Province $\left(101^{\circ} 51^{\prime} \mathrm{E}-103^{\circ} 23^{\prime} \mathrm{E}, 31^{\circ} 50^{\prime} \mathrm{N}-33^{\circ} 22^{\prime} \mathrm{N}\right)$. Yaks in these areas were kept outdoors and shared pastures with sheep and wild animals. Fresh feces were collected from the ground if the animal was observed to defecate, with care taken to avoid environmental contamination by sampling only those portions of the fecal material that had not been in contact with the ground. A total of 545 fresh fecal specimens were collected immediately post-defecation from yaks aged 2 months to 10 years. No obvious clinical signs were observed in the animals. All specimens were stored in $2.5 \%(\mathrm{w} / \mathrm{v})$ potassium dichromate solution at $4{ }^{\circ} \mathrm{C}$ until DNA extraction.

\section{DNA extraction}

Specimens were washed three times in distilled water with centrifugation at $3000 \times g$ for $10 \mathrm{~min}$ to remove the potassium dichromate. DNA was extracted from $200 \mathrm{mg}$ of each fecal specimen using the E.Z.N.A.R Stool DNA Kit (Omega Biotek Inc., Norcross, USA) according to the manufacturer's instruction. The extracted DNA was stored at $-20{ }^{\circ} \mathrm{C}$.

\section{PCR amplification}

Cryptosporidium species were detected in the fecal specimens and differentiated by PCR analysis of the small subunit rRNA (SSU rRNA) gene according to previous process [45]. C. parvum and C. ubiquitum were subtyped based on sequence analysis of the $60-\mathrm{kDa}$ glycoprotein gene (gp60) following PCR amplification [32, 46].

G. duodenalis genotyping was performed using nested PCR amplification of the the SSU rRNA region from each specimen as described previously [47]. DNA from all SSU rRNA-positive specimens were subjected to further PCR analysis to detect the presence of the glutamate dehydrogenase $(g d h)$, triose phosphate isomerase $(t p i)$, and $\beta$-giardin $(b g)$ genes based on previously described methods [48-50].

The primers used in the PCR analysis of all gene targets, the annealing temperatures, and the sizes of the expected PCR products according to previous described. The PCR reactions for all genes were conducted in $25 \mu \mathrm{L}$ reaction mixtures containing of $1 \times \mathrm{PCR}$ buffer (TaKaRa Shuzo Co., Ltd., Otsu, Japan), $200 \mu \mathrm{M}$ each dNTP, $0.4 \mu \mathrm{M}$ each primer, 1 unit of TaKaRa rTaq DNA polymerase, and $2 \mu \mathrm{L}$ of DNA. Except the SSU rRNA protocol, $1 \times$ GC buffer II and LA Taq DNA polymerase (TaKaRa Shuzo Co., Ltd.) were used instead of $1 \times$ PCR buffer and rTaq. The secondary PCR products were examined by agarose gel electrophoresis and visualised after GelRed $^{\text {Tw1 }}$ (Biotium Inc., Hayward, CA, USA) staining.

\section{Sequence analysis}

All PCR amplicons were sequenced on an ABI PRISM 3730 XL DNA Analyzer using a BigDye Terminator v3.1 Cycle Sequencing Kit (Applied Biosystems, Foster City, CA, USA). The sequence accuracy was confirmed by two-directional sequencing, and sequences were identified by alignment with reference sequences downloaded from GenBank (http://www.ncbi.nlm.nih.gov) using MEGA 5 software (http://www.megasoftware.net/). The subtypes of G. duodenalis identified at the tpi and $g d h$ genes in this study were compared with known ones using a neighbour-joining analysis of the aligned sequences using MEGA 5 software (http://www.megasoftware.net/). The reliability of these trees was assessed by the bootstrap analysis with 1000 replicates, with the substitution type of nucleotide. The nucleotide sequences obtained in this study have been deposited in GenBank under accession numbers [GenBank: KP334133-KP334150] (Additional file 1).

\section{Statistical analysis}

The $\chi^{2}$ test was used to compare the Cryptosporidium and $G$. duodenalis infection rates, and differences were considered significant when $p<0.05$.

\section{Additional file}

Additional file 1: GenBank accession numbers and nucleotide sequences in this study.

\section{Competing interests}

The authors declare that they have no competing interests.

\section{Author contributions}

$L X Z, F C J$ and $M Q$ conceived and designed the experiments; MQ, JZC, RJW, $J Q L, J Y H$, and $H Z$ performed the experiments; MQ and JQL analyzed the data; and $M Q, F C J$ and $L X Z$ wrote the manuscript. All authors have read and approved the final manuscript.

\section{Acknowledgments}

This study was supported in part by the Key Program of the National Natural Science Foundation of China (31330079), the National Natural Science Foundation of China (U1404327, 31402387), and the Innovative Scientists Cultivation Projects of Henan Province (134200510012).

\section{Author details}

${ }^{1}$ College of Animal Science and Veterinary Medicine, Henan Agricultura University, Zhengzhou 450002, P. R. China. ${ }^{2}$ International Joint Research Laboratory for Zoonotic Diseases of Henan, Zhengzhou 450002, P. R. China ${ }^{3}$ Qinghai Academy of Veterinary Medicine and Animal Science, Xining 810016, P. R. China.

Received: 17 January 2015 Accepted: 14 May 2015

Published online: 21 May 2015

\section{References}

1. Ryan UM, Cacciò SM. Zoonotic potential of Giardia. Int J Parasitol. 2013;43:943-56.

2. Fayer R. Taxonomy and species delimitation in Cryptosporidium. Exp Parasitol. 2010;124:90-7.

3. Xiao L. Molecular epidemiology of cryptosporidiosis: an update. Exp Parasitol. 2010;124:80-9. 
4. Xiao L, Fayer R. Molecular characterisation of species and genotypes of Cryptosporidium and Giardia and assessment of zoonotic transmission. Int J Parasitol. 2008;38:1239-55.

5. Baldursson $S$, Karanis P. Waterborne transmission of protozoan parasites: Review of worldwide outbreaks-an update 2004-2010. Water Res. 2011;45:6603-14.

6. Blackburn BG, Mazurek JM, Hlavsa M, Park J, Tillapaw M, Parrish M, et al. Cryptosporidiosis associated with ozonated apple cider. Emerg Infect Dis. 2006;12:684-6.

7. Kváč M, Hofmannová L, Hlásková L, Květoňová D, Vítovec J, McEvoy J, et al. Cryptosporidium erinacei n. sp. (Apicomplexa: Cryptosporidiidae) in hedgehogs. Vet Parasitol. 2014;201:9-17.

8. Ma J, Cai J, Ma J, Feng Y, Xiao L. Occurrence and molecular characterization of Cryptosporidium spp. in yaks (Bos grunniens) in China. Vet Parasitol. 2014;202:113-8.

9. Helmy YA, Krücken J, Nöckler K, von Samson-Himmelstjerna G, Zessin KH. Molecular epidemiology of Cryptosporidium in livestock animals and humans in the Ismailia province of Egypt. Vet Parasitol. 2013;193:15-24.

10. Khan SM, Debnath C, Pramanik AK, Xiao L, Nozaki T, Ganguly S. Molecular characterization and assessment of zoonotic transmission of Cryptosporidium from dairy cattle in West Bengal, India. Vet Parasitol. 2010;171:41-7.

11. Feng Y, Karna SR, Dearen TK, Singh DK, Adhikari LN, Shrestha A, et al. Common occurrence of a unique Cryptosporidium ryanae variant in zebu cattle and water buffaloes in the buffer zone of the Chitwan National Park, Nepal. Vet Parasitol. 2012;85:309-14.

12. Ng JS, Eastwood K, Walker B, Durrheim DN, Massey PD, Porigneaux P, et al. Evidence of Cryptosporidium transmission between cattle and humans in northern New South Wales. Exp Parasitol. 2012;130:437-41.

13. Thompson RCA. The zoonotic significance and molecular epidemiology of Giardia and giardiasis. Vet Parasitol. 2004;126:15-35.

14. Feng Y, Xiao L. Zoonotic potential and molecular epidemiology of Giardia species and giardiasis. Clin Microbiol Rev. 2011;24:110-40.

15. Bai Y, Suo N, Jia G, Xing S, Ma Z, Zeng B. Investigation of cryptosporidiosis of yak calves in Tongde County. Sichuan Anim Vet Sci. 2001;28:22 (in Chinese).

16. Dou CX. Investigation of cryptosporidiosis of yak calves in Huangyuan County in Qinghai Province. Anim Husban Feed Sci. 2007;28:14 (in Chinese).

17. Feng $Y$, Ortega $Y$, He G, Das $P, X u$ M, Zhang $X$, et al. Wide geographic distribution of Cryptosporidium bovis and the deer-like genotype in bovines. Vet Parasitol. 2007;144:1-9.

18. Karanis P, Plutzer J, Halim NA, Igori K, Nagasawa H, Ongerth J, et al. Molecular characterization of Cryptosporidium from animal sources in Qinghai province of China. Parasitol Res. 2007;101:1575-80.

19. Ma L, Lu Y, Cai Q, Wang G, Niu X, Ye C, et al. Serological investigation on cryptosporidiosis of yak from Qinghai Province. Acta Ecol Anim Domast. 2011:32:47-9 (in Chinese).

20. Mi R, Wang X, Li C, Huang Y, Zhou P, Li Z, et al. Prevalence and genetic characterization of Cryptosporidium in yaks in Qinghai Province of China. PLoS One. 2013;8:e74985.

21. Wang C, Liu H. Investigation of cryptosporidiosis of yak in Hualong County in Qinghai Province. Chin J Vet Med. 2007:43:31 (in Chinese).

22. Zhang J, Xu J, Shen X. Investigation of Cryptosporidium infectionin cattle in Qinghai Province. Qinghai J Anim Vet Sci. 2006;36:16-7 (in Chinese).

23. Zhou C, He G, Zhang L. Investigation on the Cryptosporidium infection in yak. Chin J Zoon. 2009;25:389-90 (in Chinese).

24. Qin SY, Zhang XX, Zhao GH, Zhou DH, Yin MY, Zhao Q, et al. First report of Cryptosporidium spp. in white yaks in China. Parasit Vectors. 2014;7:230.

25. Liu A, Zhang X, Zhang L, Wang R, Li X, Shu J, et al. Occurrence of bovine giardiasis and endemic genetic characterization of Giardia duodenalis isolates in Heilongjiang Province, in the Northeast of China. Parasitol Res. 2012;111:655-61.

26. Wang $H$, Zhao G, Chen G, Jian F, Zhang S, Feng C, et al. Multilocus genotyping of Giardia duodenalis in dairy cattle in Henan China. PLoS One. 2014;9:e100453.

27. Mark-Carew MP, Wade SE, Chang YF, Schaaf S, Mohammed HO. Prevalence of Giardia duodenalis assemblages among dairy herds in the New York City Watershed. Vet Parasitol. 2012;185:151-7.

28. Cui Z, Wang R, Huang J, Wang H, Zhao J, Luo N, et al. Cryptosporidiosis caused by Cryptosporidium parvum subtype IIdA15G1 at a dairy farm in Northwestern China. Parasit Vectors. 2014;7:529.
29. Huang J, Yue D, Qi M, Wang R, Zhao J, Li J, et al. Prevalence and molecular characterization of Cryptosporidium spp. and Giardia duodenalis in dairy cattle in Ningxia, northwestern China. BMC Vet Res. 2014;10:292.

30. Wang $R$, Wang $H$, Sun $Y$, Zhang L, Jian F, Qi M, et al. Characteristics of Cryptosporidium transmission in preweaned dairy cattle in henan, China. J Clin Microbiol. 2011:49:1077-82.

31. Zhang W, Wang R, Yang F, Zhang L, Cao J, Zhang X, et al. Distribution and genetic characterizations of Cryptosporidium spp. in pre-weaned dairy calves in Northeastern China's Heilongjiang Province. PLoS One. 2013;8:e54857.

32. Li N, Xiao L, Alderisio K, Elwin K, Cebelinski E, Chalmers R, et al. Subtyping Cryptosporidium ubiquitum, a zoonotic pathogen emerging in humans. Emerg Infect Dis. 2014;20:217-24.

33. Wang R, Li G, Cui B, Huang J, Cui Z, Zhang S, et al. Prevalence, molecular characterization and zoonotic potential of Cryptosporidium spp. in goats in Henan and Chongqing, China. Exp Parasitol. 2014;142:11-6.

34. Mi R, Wang X, Huang Y, Zhou P, Liu Y, Chen Y, et al. Prevalence and molecular characterization of Cryptosporidium in goats across four provincial level areas in China. PLoS One. 2014;9:e111164.

35. Wang R, Zhang L, Axén C, Bjorkman C, Jian F, Amer S, et al. Cryptosporidium parvum IId family: clonal population and dispersal from Western Asia to other geographical regions. Sci Rep. 2014;4:4208.

36. Ye J, Xiao L, Ma J, Guo M, Liu L, Feng Y. Anthroponotic enteric parasites in monkeys in public park, China. Emerg Infect Dis. 2012;18:1640-3.

37. Li N, Xiao L, Wang L, Zhao S, Zhao X, Duan L, et al. Molecular surveillance of Cryptosporidium spp., Giardia duodenalis, and Enterocytozoon bieneusi by genotyping and subtyping parasites in wastewater. PLoS Negl Trop Dis. 2012;6:e1809.

38. Wang L, Zhang H, Zhao X, Zhang L, Zhang G, Guo M, et al. Zoonotic Cryptosporidium species and Enterocytozoon bieneusi genotypes in HIV-positive patients on antiretroviral therapy. J Clin Microbiol. 2013;51:557-63.

39. Misic Z, Abe N. Subtype analysis of Cryptosporidium parvum isolates from calves on farms around Belgrade, Serbia and Montenegro, using the $60 \mathrm{kDa}$ glycoprotein gene sequences. Parasitology. 2007;134:351-8.

40. Quílez J, Torres E, Chalmers RM, Hadfield SJ, Del Cacho E, Sánchez-Acedo C. Cryptosporidium genotypes and subtypes in lambs and goat kids in Spain. Appl Environ Microbiol. 2008;74:6026-31.

41. Chalmers RM, Smith RP, Hadfield SJ, Elwin K, Giles M. Zoonotic linkage and variation in Cryptosporidium parvum from patients in the United Kingdom. Parasitol Res. 2011;108:1321-5.

42. Sulaiman IM, Hira PR, Zhou L, Al-Ali FM, Al-Shelahi FA, Shweiki HM, et al. Unique endemicity of cryptosporidiosis in children in Kuwait. J Clin Microbiol. 2005;43:2805-9.

43. Barigye R, Dyer NW, Newell TK, Khaitsa ML, Trout JM, Santin M, et al. Molecular and immunohistochemical detection of assemblage E, Giardia duodenalis in scouring North Dakota calves. Vet Parasitol. 2008;157:196-202.

44. Liu A, Yang F, Shen Y, Zhang W, Wang R, Zhao W, et al. Genetic analysis of the Gdh and Bg Genes of animal-derived Giardia duodenalis isolates in Northeastern China and evaluation of zoonotic transmission potential. PLoS One. 2014;9:e95291.

45. Alves M, Xiao L, Sulaiman I, Lal AA, Matos O, Antunes F. Subgenotype analysis of Cryptosporidium isolates from humans, cattle, and zoo ruminants in Portugal. J Clin Microbiol. 2003;41:2744-7.

46. Jiang J, Alderisio KA, Xiao L. Distribution of Cryptosporidium genotypes in storm event water samples from three watersheds in New York. Appl Environ Microbiol. 2005;71:4446-54.

47. Appelbee AJ, Frederick LM, Heitman TL, Olson ME. Prevalence and genotyping of Giardia duodenalis from beef calves in Alberta, Canada. Vet Parasitol. 2003;112:289-94.

48. Lalle M, Pozio E, Capelli G, Bruschi F, Crotti D, Cacciò SM. Genetic heterogeneity at the $\beta$-giardin locus among human and animal isolates of Giardia duodenalis and identification of potentially zoonotic sub-genotypes. Int J Parasitol. 2005;35:207-13.

49. Cacciò SM, Beck R, Lalle M, Marinculic A, Pozio E. Multilocus genotyping of Giardia duodenalis reveals striking differences between assemblages $A$ and B. Int J Parasitol. 2008;38:1523-31.

50. Sulaiman IM, Fayer R, Bern C, Gilman RH, Trout JM, Schantz PM, et al. Triosephosphate isomerase gene characterization and potential zoonotic transmission of Giardia duodenalis. Emerg Infect Dis. 2003;9:1444-52. 